\title{
PRL-3 and E-cadherin show mutual interactions and participate in lymph node metastasis formation in gastric cancer
}

\author{
Anna Pryczynicz • Katarzyna Guzińska-Ustymowicz • \\ Katarzyna Niewiarowska • Dariusz Cepowicz • \\ Andrzej Kemona
}

Received: 21 January 2014 / Accepted: 17 March 2014 / Published online: 3 April 2014

(C) The Author(s) 2014. This article is published with open access at Springerlink.com

\begin{abstract}
E-cadherin, a transmembrane adhesion molecule, and phosphatase of regenerating liver 3 (PRL-3) protein, a member of the family of tyrosine phosphatases, seem to be responsible for cancer cell migration. Therefore, the study objective was to determine a correlation between PRL-3 and E-cadherin, to assess their expression in neoplastic tissue and normal mucosa of the stomach, to analyze their effect on cancer advancement, and to evaluate their potential as prognostic markers in gastric cancer. The expressions of PRL-3 and E-cadherin were assessed immunohistochemically in 71 patients with gastric cancer. Positive expression of PRL-3 was observed in $42.2 \%$ of gastric cancer cases, whereas Ecadherin expression was abnormal in $38 \%$ of cases. The study revealed that the positive PRL-3 expression and abnormal Ecadherin expression were associated with mucinous gastric carcinoma and lymph node involvement. The former was also related to the infiltrating type of tumor and abnormal Ecadherin expression. The expression of PRL-3, but not of Ecadherin, was associated with shorter survival of patients. PRL-3 and E-cadherin exhibit interactions in gastric cancer and are involved in the formation of lymph node metastases. The PRL-3 protein can be an independent predictive factor of overall survival in gastric cancer patients.
\end{abstract}

Keywords E-cadherin $\cdot$ Gastric cancer $\cdot$ Metastases $\cdot$ PRL-3

\footnotetext{
A. Pryczynicz $(\bowtie) \cdot$ K. Guzińska-Ustymowicz $\cdot$ K. Niewiarowska $\cdot$ A. Kemona

Department of General Pathomorphology, Medical University of Bialystok, ul. Waszyngtona 13, 15-269 Bialystok, Poland

e-mail: pryczynicz.anna@gmail.com

D. Cepowicz

Second Department of General and Gastroenterological Surgery, Medical University of Bialystok, Bialystok, Poland
}

\section{Introduction}

The phosphatase of regenerating liver 3 (PRL-3) protein belongs to the family of tyrosine phosphatases, with a unique $\mathrm{COOH}$-terminal prenylation motif, and it is thus involved in a major reaction for the cell, i.e., dephosphorylation of tyrosine residues deactivating enzymes. Although its physiological role is poorly investigated, literature data suggest that PRL-3 takes part in neoformation, i.e., in migration, metastasizing, and angiogenesis [1, 2]. However, factors that regulate PRL-3 expression as well as its enzymes are not well known, and researchers are still searching for pathways and processes associated with the protein involvement. A few studies have revealed a link between PRL-3 and proteins responsible for cytoskeleton rebuilding [3-7]. Regulation of cell adhesion is another mechanism of the protein in the promotion of cancer cell invasion and metastasizing [8,9]. The PRL-3 is also involved in tumor growth through the mechanism of epithelial-mesenchymal transformation (EMT). PRL-3 activates the Akt pathway, which results in glycogen synthase kinase $3 \beta$ (GSK-3 $\beta$ ) inactivation and then in overexpression of mesenchymal markers - vimentin, fibronectin, and Snailand a decrease in $\gamma$-catenins, integrin $\beta 3$, and E-cadherin responsible for cell adhesion [10].

E-cadherin is a transmembrane protein, which, in normal epithelium, is responsible for intracellular interactions. Its cytoplasmic domain interacts with $\beta$-catenin or $\gamma$-catenin. The complex that is formed binds $\alpha$-catenin, which directly affects the cytoskeleton $[11,12]$. In cancers, dysfunction of Ecadherin induced by lack of the cytoplasmic domain (no interaction with catenins) or extracellular domain (no interaction with adjacent cells with a simultaneous accumulation of catenins) and changes in mutations are observed. These disorders can lead to the detachment of cancer cells from the primary tumor mass and thus increase their invasiveness [13, 14]. 
Considering the similar role of both proteins in the migration of cancer cells and EMT, the objective of the current study was to determine the correlation between the PRL-3 protein and E-cadherin, to assess their expression in cancer tissue and in normal gastric mucosa, as well as to investigate their effect on tumor stage. Also, the prognostic potential of both proteins was assessed in gastric cancer.

\section{Material and methods}

The study involved 71 patients with gastric cancer treated surgically in the Second Department of General Surgery and Gastroenterology in the years 2005-2010. As a control, healthy gastric mucosa was collected from a stomach fragment removed during therapeutic surgery. The postoperative material was fixed in buffered and paraffin-embedded formalin. From paraffin blocks, 4- $\mu \mathrm{m}$ sections were cut off and stained with hematoxylin-eosin $(\mathrm{H}+\mathrm{E})$. Routine histopathological analysis included determination of tumor histological type, malignancy grade $(\mathrm{G})$, anatomoclinical stage (pT), and lymph node metastases. Gastric cancers were also divided according to Lauren's classification [15], Goseki's classification [16], and Borrmann's classification [17]. Also, the presence of Helicobacter pylori infection was assessed in Giemsastained preparations.

Immunohistochemical analysis Tissue blocks were cut using a microtome into $4-\mu \mathrm{m}$-thick sections on silanized glasses. The sections were deparaffinized in xylenes and hydrated in alcohols. In order to exhibit antigen, the tissue sections were heated in a microwave for $15 \mathrm{~min}$ in citrate buffer $(\mathrm{pH}=6.0)$. Then, they were incubated with $0.5 \%$ hydrogen peroxide in methanol to block endogenous peroxidase and, next, with mouse anti-PRL-3 antibody (clone 3B6; Attogen Biomedical Research, USA; 1:500 dilution) overnight at $4{ }^{\circ} \mathrm{C}$ and with mouse monoclonal anti-E-cadherin antibody (clone 36B5). Following streptavidin-biotin reaction (biotinylated secondary antibody, streptavidin-HRP; Novocastra, UK), the antigenantibody complex was visualized by application of chromogen 3,3'-diaminobenzidine (DAB; Novocastra, UK). The expressions of the proteins were assessed using the semiquantitative method, which defined PRL-3 expression as positive when the reaction was visible in more than $5 \%$ of cancer cells and negative when there was no reaction or it was present in $<5 \%$ of cells. For E-cadherin, the reaction was normal when the membranous expression of the protein was present in $>30 \%$ of cells; it was abnormal when negative or when membranous expression was present in $<30 \%$ of cells or in the case of cytoplasmic expression. Positive reaction was calculated in at least 500 cancer cells in each tissue section using a light microscope $(\times 400)$.
The statistical analysis was based on Fisher's test and $\chi^{2}$ test. Log-rank test which is according to Kaplan-Meier survival analysis approach was employed to compare the overall survival rate of patients. A Cox proportional hazard model was used for univariate and multivariate analyses. A $p$ value of $<0.05$ was considered statistically significant. The statistics was performed using STATISTICA 10 (Poland).

\section{Results}

PRL-3 and E-cadherin expression in normal gastric mucosa and in gastric cancer

Normal gastric mucosa did not show PRL-3 expression, whereas E-cadherin was present on the cytoplasmic membrane of most glandular cells. The neoplastic tissue had a positive expression of PRL-3 in 42.2\% (30/71) of gastric cancer cases, whereas abnormal expression of E-cadherin was observed in $38 \%$ (27/71) of cases (Fig. 1).

PRL-3 and E-cadherin expression in correlation to clinicopathological parameters in gastric cancer

Statistical analysis revealed no correlations of the expression of PRL-3 and E-cadherin with sex, age, tumor location, infiltration depth (pT), malignancy grade, tumor type according to Goseki and Lauren, and the presence of H. pylori infection. The positive expression of PRL-3 and abnormal expression of E-cadherin were shown to be associated with a mucinous type of gastric cancer ( $p=0.002$ and $p=0.012$, respectively). Positive expression of PRL-3 was also related with the infiltrating type of tumor in Borrmann's classification $(p=0.037)$. Patients with local lymph node involvement also had increased PRL-3 and abnormal E-cadherin expression in primary tumor $(p<0.001)$. Moreover, positive PRL expression was associated with abnormal expression of E-cadherin $(p=0.007)$ (Table 1).

Correlation of PRL-3 and E-cadherin expression with patients' survival

Overall assessment of patients' survival showed a lack of correlation between the expression of E-cadherin and survival rate $(p=0.510)$. However, the postoperative time of overall survival in patients with positive PRL-3 expression was markedly shorter ( $p=0.023$ ) (Fig. 2).

Prognostic factors of gastric cancer

As shown by univariate Cox regression analysis, tumor location, histological malignancy grade, tumor type in Lauren's classification, and positive PRL-3 expression were essential 

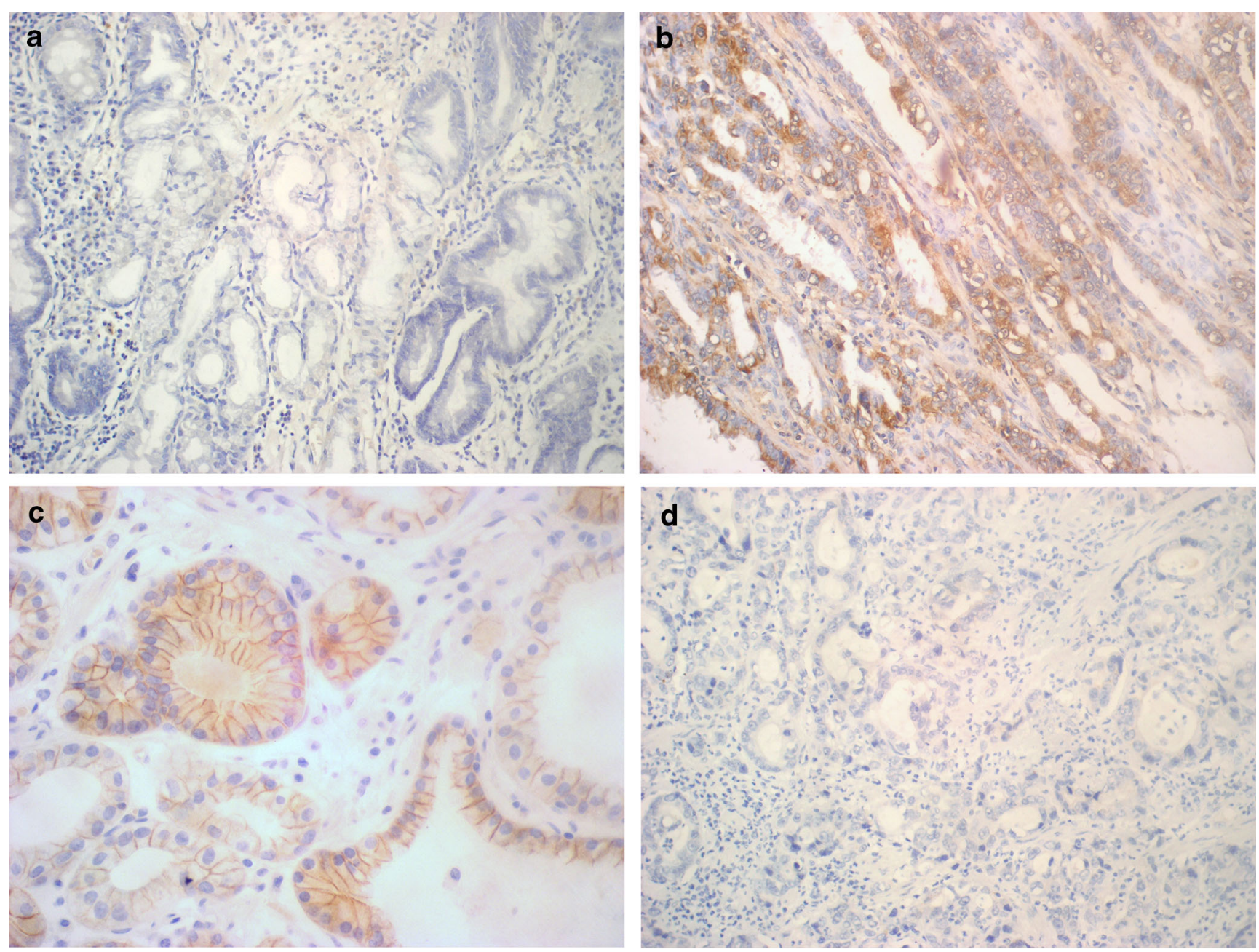

Fig. 1 Immunohistochemical staining. a PRL-3 expression in the gastric mucosa. b Positive cytoplasmic PRL-3 reaction in gastric cancer cells. c Cytoplasmic membrane expression of E-cadherin in the gastric mucosa. $\mathbf{d}$

predictive factors of overall survival among gastric cancer patients ( $p=0.046,0.004,0.021$, and 0.002 , respectively). Malignancy grade, tumor type in Lauren's classification, and positive PRL-3 expression were independent predictive factors of overall survival for these patients $(p=0.006,0.011$, and 0.001 , respectively) (Table 2).

\section{Discussion}

EMT is a physiological process of growing embryos during which epithelial cells are transformed into mesenchymal cells. In a similar way, cancer cells of epithelial origin change into mobile mesenchymal cells. Cell junctions are lost, and cancer cells in this form are able to migrate to remote parts of the body. After being released from the primary tumor, they invade the surrounding tissues, penetrate lymphatic or blood vessels, and migrate through the vascular wall, where they eventually settle, proliferate, and induce angiogenesis. There,
Negative of E-cadherin expression in gastric cancer cells. Original magnification: $\times 200$ and $\times 400$

they become transformed into epithelial cells and adhere tightly to one another to form a metastatic tumor [18]. The ability of cancer cells to disseminate from the primary tumor to lymph nodes and to the nearest and distant tissues and organs is a major feature of malignant neoplasms and the main cause of therapeutic failure. Since tumor stage pTNM is the key factor, with the greatest significance in the treatment of gastric cancer patients, research into markers involved in metastasizing has been intensified. E-cadherin, a transmembrane adhesion molecule and PRL-3 belonging to the family of tyrosine phosphatases seem to be particularly responsible for the migration of cancer cells. Wang et al. [19] have been the first to suggest the involvement of PRL-3 in EMT. They have put forward the hypothesis that PRL-3 activates the Akt pathway through direct inhibition of PTEN (inhibitor for PI3K), which results in GSK-3 $\beta$ inactivation. Next, Liu et al. [20] have presented evidence for PRL-3 involvement in EMT via cadherin-related signaling pathway. Most likely, PRL-3 plays a major role in direct inhibition of the expression 
Table 1 Relationship between the expressions of PRL-3 and Ecadherin proteins and clinicopathological parameters in gastric cancer
Significant relationship is marked in italics

Missing data were removed in pairs

\begin{tabular}{|c|c|c|c|c|c|c|}
\hline \multirow[t]{2}{*}{ Variables } & \multicolumn{2}{|c|}{ PRL-3 expression } & \multirow[t]{2}{*}{$p$ value } & \multicolumn{2}{|c|}{ E-cadherin expression } & \multirow[t]{2}{*}{$p$ value } \\
\hline & Absent & Present & & Abnormal & Normal & \\
\hline \multicolumn{7}{|l|}{ Age } \\
\hline$\leq 50$ & 10 & 10 & \multirow[t]{2}{*}{0.415} & 12 & 12 & \multirow[t]{2}{*}{0.358} \\
\hline$>50$ & 31 & 20 & & 15 & 32 & \\
\hline \multicolumn{7}{|l|}{ Gender } \\
\hline Male & 28 & 21 & \multirow[t]{2}{*}{0.880} & 21 & 30 & \multirow[t]{2}{*}{0.591} \\
\hline Female & 13 & 9 & & 6 & 14 & \\
\hline \multicolumn{7}{|l|}{ Location } \\
\hline Upper $1 / 3$ & 2 & 4 & \multirow[t]{3}{*}{0.114} & 1 & 1 & \multirow[t]{3}{*}{0.568} \\
\hline Middle 1/3 & 16 & 14 & & 14 & 16 & \\
\hline Lower $1 / 3$ & 23 & 12 & & 13 & 26 & \\
\hline \multicolumn{7}{|l|}{ Depth of invasion } \\
\hline $\mathrm{T} 1$ & 5 & 1 & \multirow[t]{3}{*}{0.114} & 1 & 5 & \multirow[t]{3}{*}{0.794} \\
\hline $\mathrm{T} 2$ & 11 & 6 & & 6 & 8 & \\
\hline $\mathrm{T} 3$ & 25 & 23 & & 21 & 30 & \\
\hline \multicolumn{7}{|l|}{ Histological differentiation } \\
\hline Moderately differentiated & 20 & 9 & \multirow[t]{2}{*}{0.115} & 12 & 23 & \multirow[t]{2}{*}{0.585} \\
\hline Poorly differentiated & 21 & 21 & & 15 & 21 & \\
\hline \multicolumn{7}{|l|}{$\mathrm{Hp}$} \\
\hline Adenocarcinoma & 36 & 17 & \multirow[t]{2}{*}{0.002} & 21 & 42 & \multirow[t]{2}{*}{0.012} \\
\hline Adenocarcinoma mucinosum & 5 & 13 & & 10 & 5 & \\
\hline \multicolumn{7}{|l|}{ Goseki's classification } \\
\hline I & 7 & 4 & 0.254 & 3 & 5 & 0.188 \\
\hline II & 8 & 10 & & 9 & 11 & \\
\hline III & 5 & 5 & & 6 & 5 & \\
\hline IV & 14 & 18 & & 17 & 13 & \\
\hline Lauren's classification & & & & & & \\
\hline Intestinal type & 31 & 16 & 0.051 & 16 & 35 & 0.086 \\
\hline Diffuse type & 10 & 14 & & 11 & 9 & \\
\hline Borrmann's classification & & & & & & \\
\hline I (polypoid) & 4 & 1 & 0.037 & 3 & 4 & 0.935 \\
\hline II (fungating) & 8 & 4 & & 8 & 13 & \\
\hline III (ulcerated) & 26 & 17 & & 19 & 27 & \\
\hline IV (infiltrative) & 3 & 8 & & 7 & 10 & \\
\hline Lymph node metastasis & & & & & & \\
\hline Absent & 40 & 9 & $<0.001$ & 10 & 45 & $<0.001$ \\
\hline Present & 1 & 21 & & 17 & 1 & \\
\hline Helicobacter pylori infection & & & & & & \\
\hline Absent & 16 & 18 & 0.373 & 15 & 20 & 0.320 \\
\hline Present & 20 & 17 & & 12 & 24 & \\
\hline E-cadherin expression & & & & & & \\
\hline Abnormal & 9 & 14 & 0.007 & - & - & - \\
\hline Normal & 28 & 10 & & & & \\
\hline
\end{tabular}

of E-cadherin and CDH22 [20]. In our study, we analyzed the immunohistochemical correlation between the expression of PRL-3 and E-cadherin in gastric cancer and observed a correlation between increased PRL-3 expression and abnormal E- cadherin expression ( $p=0.007)$, which indicates that they may interact.

We also compared the relationship of PRL-3 and Ecadherin with clinicopathological parameters in gastric cancer. 

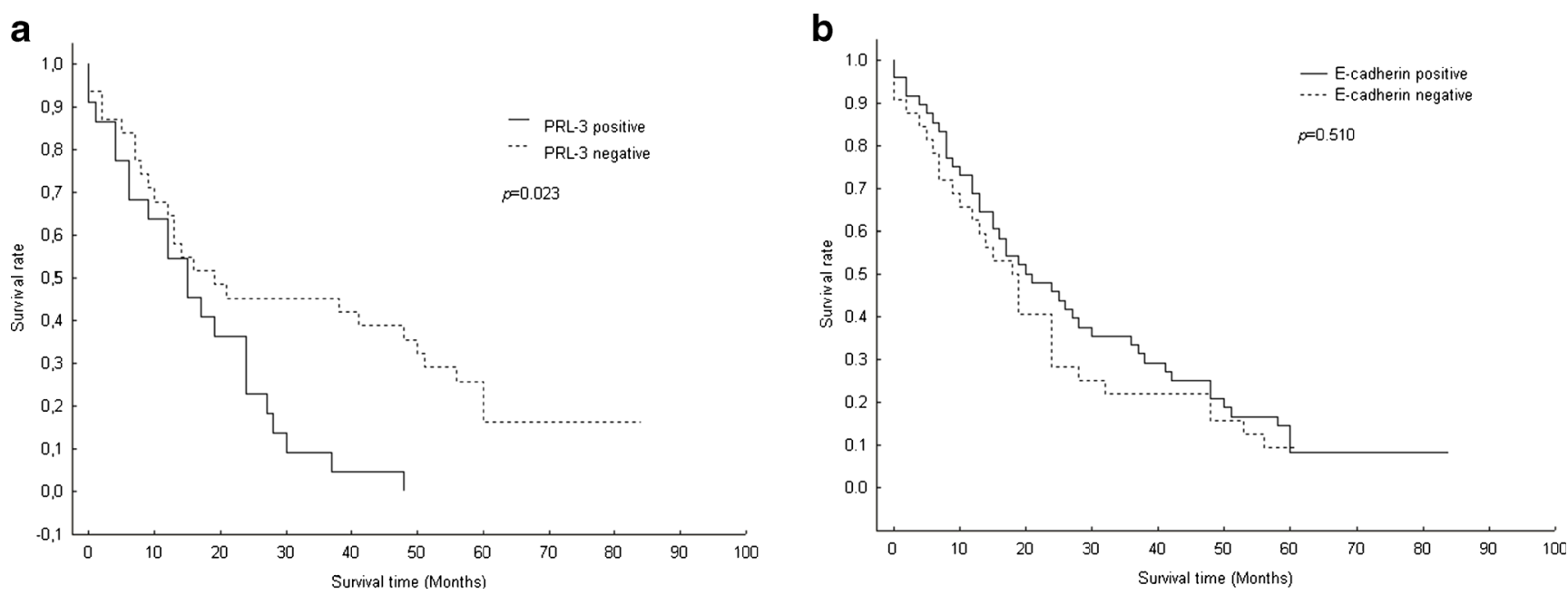

Fig. 2 Postoperative overall survival of patients with gastric cancer. Comparison of postoperative survival according to the expressions of PRL-3 and Ecadherin

We revealed a correlation of positive PRL-3 and abnormal Ecadherin with mucinous type of gastric cancer. Similar observations have been reported by other authors, indicating a relationship between these proteins and signet ring cell-type carcinoma [21, 22]. It is likely that an abnormal expression of E-cadherin and an overexpression of PRL-3 are associated with the loss of cell junctions and loosening of cells in this histological type. Importantly, both proteins were found to correlate with the presence of local lymph node metastases. Thus, PRL-3 and E-cadherin seem to exert an extremely significant effect on the spread of gastric cancer through the lymphatic pathway. Our findings are compatible with earlier literature data [21-24].

We also analyzed whether the proteins could be prognostic factors in gastric cancer. Only the positive expression of PRL-
3 was found to correlate with shorter survival of patients. We also demonstrated that PRL-3 was an independent prognostic factor and could be used as a therapeutic target in this cancer. Ooki et al. [24] have additionally observed that PRL-3 overexpression is an independent prognostic factor in patients with gastric cancer without metastases to local lymph nodes as compared to patients with lymph node involvement. Although other studies, including the research conducted by Li et al. [25], have shown that also an abnormal expression of Ecadherin can be a strong independent prognostic factor of the overall survival of patients with gastric cancer, we did not observe such correlations for the expression of $\mathrm{E}$ cadherin.

In conclusion, our study found a significant correlation between PRL-3 protein and E-cadherin. However, it is the

Table 2 Univariate and multivariate analysis of clinicopathological factors in gastric cancer

\begin{tabular}{|c|c|c|c|c|}
\hline Variables & Univariate $p$ value & Multivariate $p$ value & Hazard ratio & $95 \% \mathrm{CI}$ \\
\hline Age $(\leq 50$ vs. $>50)$ & 0.081 & - & 1.600 & $0.942-2.715$ \\
\hline Gender (male vs. female) & 0.641 & - & 1.137 & $0.660-1.959$ \\
\hline Location (upper $1 / 3$, middle $1 / 3$, vs. lower $1 / 3$ ) & 0.873 & - & 1.042 & $0.627-1.730$ \\
\hline Depth of invasion (T1, T2, vs. T3) & 0.046 & 0.078 & 1.852 & $1.008-3.403$ \\
\hline Histological differentiation (moderately diff. vs. poorly diff.) & 0.641 & - & 1.145 & $0.646-2.029$ \\
\hline Hp (adc. vs. adc. mucinosum) & 0.004 & 0.006 & 0.293 & $0.127-0.678$ \\
\hline Goseki's classification (I and III vs. II and IV) & 0.864 & - & 1.073 & $0.476-2.419$ \\
\hline Lauren's classification (intestinal type vs. diffuse type) & 0.021 & 0.011 & 2.422 & $1.140-5.143$ \\
\hline Borrmann's classification (I and II vs. III and IV) & 0.068 & - & 0.587 & $0.331-1.040$ \\
\hline Lymph node metastasis (absent vs. present) & 0.372 & - & 0.705 & $0.327-1.519$ \\
\hline Helicobacter pylori infection (absent vs. present) & 0.713 & - & 1.109 & $0.635-1.937$ \\
\hline PRL-3 expression (absent vs. present) & 0.002 & 0.001 & 4.059 & $1.615-10.198$ \\
\hline E-cadherin expression (abnormal vs. normal) & 0.318 & - & 0.713 & $0.367-1.384$ \\
\hline
\end{tabular}

Significant relationship is marked in italics

Borrmann's classification: I (polypoid), II (fungating), III (ulcerated), and IV (infiltrative)

diff. differentiated, adc. adenocarcinoma, $C I$ confidence interval 
PRL-3 protein which seems to be more important in the growth of gastric cancer.

\section{Conflicts of interest None}

Open Access This article is distributed under the terms of the Creative Commons Attribution License which permits any use, distribution, and reproduction in any medium, provided the original author(s) and the source are credited.

\section{References}

1. Zeng Q, Hong W, Tan YH. Mouse PRL-2 and PRL-3, two potentially prenylated protein tyrosine phosphatases homologous to PRL-1. Biochem Biophys Res Commun. 1998;244:421-7.

2. Guzińska-Ustymowicz K, Pryczynicz A. PRL-3, an emerging marker of carcinogenesis, is strongly associated with poor prognosis. Anticancer Agents Med Chem. 2011;11:99-108.

3. Fiordalisi JJ, Keller PJ, Cox AD. PRL tyrosine phosphatases regulate rho family GTPases to promote invasion and motility. Cancer Res. 2006;66:3153-61.

4. Forte E, Orsatti L, Talamo F, Barbato G, De Francesco R, Tomei L. Ezrin is a specific and direct target of protein tyrosine phosphatase PRL-3. Biochim Biophys Acta. 2008;1783:334 44.

5. Khanna C, Wan X, Bose S, Cassaday R, Olomu O, Mendoza A, et al. The membrane-cytoskeleton linker ezrin is necessary for osteosarcoma metastasis. Nat Med. 2004;10:182-6.

6. Mizuuchi E, Semba S, Kodama Y, Yokozaki H. Down-modulation of keratin 8 phosphorylation levels by PRL-3 contributes to colorectal carcinoma progression. Int J Cancer. 2009;124:1802-10.

7. Zheng P, Liu YX, Chen L, Liu XH, Xiao ZQ, Zhao L, et al. Stathmin, a new target of PRL-3 identified by proteomic methods, plays a key role in progression and metastasis of colorectal cancer. J Proteome Res. 2010;9:4897-905.

8. Peng L, Jin G, Wang L, Guo J, Meng L, Shou C. Identification of integrin alphal as an interacting protein of protein tyrosine phosphatase PRL-3. Biochem Biophys Res Commun. 2006;342:179-83.

9. Peng L, Xing X, Li W, Qu L, Meng L, Lian S, et al. PRL-3 promotes the motility, invasion, and metastasis of LoVo colon cancer cells through PRL-3-integrin beta1-ERK1/2 and-MMP2 signaling. Mol Cancer. 2009;8:110.

10. Wang Y, Li ZF, He J, Li YL, Zhu GB, Zhang LH, et al. Expression of the human phosphatases of regenerating liver (PRLs) in colonic adenocarcinoma and its correlation with lymph node metastasis. Int J Color Dis. 2007;22:1179-84.
11. Van Roy F, Berx G. The cell-cell adhesion molecule E-cadherin. Cell Mol Life Sci. 2008;65:3756-88.

12. Carneiro $P$ et al. E-cadherin dysfunction in gastric cancer - cellular consequences, clinical application and open questions. FEBS Lett. 2012;586:2981-9.

13. Birchmeier W, Behrens J. Cadherin expression in carcinomas: role in the formation of cell junctions and the prevention of invasiveness. Biochim Biophys Acta. 1994;1198:11-26.

14. Birchmeier W, Weidner KM, Hulsken J. Molecular mechanism leading to cell junction (cadherin) deficiency in invasive carcinomas. Semin Cancer Biol. 1993;4:231-9.

15. Lauren P. The two histological main types of gastric carcinoma: diffuse and so-called intestinal-type carcinoma. Acta Pathol Microbiol Scand. 1965;64:31-49.

16. Kubo G, Kubo T, Kubo K. Differences in the mode of extension of gastric cancer classified by histological type: new histological classification of gastric carcinoma. Gut. 1992;33:606-12.

17. Borrmann R. Geshwulste des Magens und Duodenums. In: Henker F, Lubarsh D, editors. Handbuchder Spezieller Pathologischen: Anatomie und Histolgie, vol. IV. Berlin: Springer; 1926. p. 865.

18. Thiery JP. Epithelial-mesenchymal transitions in development and pathologies. Curr Opin Cell Biol. 2003;15:740-6.

19. Wang H, Quah SY, Dong JM, et al. PRL-3 down-regulates PTEN expression and signals trough PI3K to promote epithelialmesenchymal transition. Cancer Res. 2007;67:2922-6.

20. Liu Y, Zhou J, Chen J, Gao W, Le Y, Ding Y, et al. PRL-3 promotes epithelial mesenchymal transition by regulating cadherin directly. Cancer Biol Ther. 2009;8:1352-9.

21. Lazăr D, Tăban S, Ardeleanu C, Dema A, Sporea I, Cornianu M, et al. The immunohistochemical expression of E-cadherin in gastric cancer; correlations with clinicopathological factors and patients' survival. Rom J Morphol Embryol. 2008;49:459-67.

22. Bilici A, Ustaalioglu BB, Yavuzer D, Seker M, Mayadagli A, Gumus M. Prognostic significance of high phosphatase of regenerating liver-3 expression in patients with gastric cancer who underwent curative gastrectomy. Dig Dis Sci. 2012;57: $1568-75$.

23. Tang B, Peng ZH, Yu PW, Yu G, Qian F. Expression and significance of $\mathrm{Cx} 43$ and $\mathrm{E}$-cadherin in gastric cancer and metastatic lymph nodes. Med Oncol. 2011;28:502-8.

24. Ooki A, Yamashita K, Kikuchi S, Sakuramoto S, Katada N, Watanabe M. Phosphatase of regenerating liver-3 as a prognostic biomarker in histologically node-negative gastric cancer. Oncol Rep. 2009;21:1467-75.

25. Li Y, Chen CQ, He YL, Cai SR, Yang DJ, He WL, et al. Abnormal expression of E-cadherin in tumor cells is associated with poor prognosis of gastric carcinoma. J Surg Oncol. 2012;106: 304-10. 